\title{
Fertilizer use pattern on agriculture in Salua area of Chougachha upazila, Jessore, Bangladesh
}

\author{
Rezaul Karim and Mst. Afia Aktar \\ Dept. of Environmental Science and Technology, Jessore University of Science and Technology (JUST), \\ Jessore-7408, Bangladesh
}

\begin{abstract}
Agriculture is one of the important issues of Bangladesh where a larger share of the people related to it for their livelihood, food and socio-economics. Farmers in Bangladesh mostly depend on chemical fertilizer within the auspicious of conventional agriculture for higher production without or little application of organic or compost fertilizers. Such a fertilizer management practice in agriculture not only causes massive deterioration of soil fertility but the farmers are also being hampered economically for higher price of chemical fertilizers. This experiment was conducted to focus mainly on the fertilizer usage and agricultural practices of the local farmers in Salua Area of Chougachha Upazila, Jessore district, Bangladesh. This study identified the reasons of using chemical fertilizers or causes for not using environmental friendly and beneficial compost in soils. This survey was conducted to know the insights of fertilizer usage pattern, and to identify causes why people are so much dependent on chemical fertilizer although it is expensive and sometimes harmful for soil, water and environment. The result of the present study showed that lack of knowledge, availability and lack of getting opportunity towards organic based fertilizers are the key reasons of not using compost fertilizer during cultivation of crops by the farmers.
\end{abstract}

Keywords: Agriculture, Chemical fertilizers, Compost and Fertilizer application practice

Please cite this article as: Karim, R. and Aktar, A. M. (2015). Fertilizer use pattern on agriculture in Salua Area of Chougachha upazila, Jessore, Bangladesh. Journal of Bioscience and Agriculture Research 03(02): 96103.

This article is distributed under terms of a Creative Common Attribution 4.0 International License

\section{Introduction}

Bangladesh is mainly an agriculture based country in terms of food security and economy where $76 \%$ of the total population lives in rural area and $90 \%$ of them are directly related with agriculture and $50 \%$ of the labor force engaged with agricultural activities (GoB, 2009). Agricultural sector is being considered as the backbone of Bangladeshi economy, and it is continuing to be the dominant driving force for the growth and development of its national economy. Sufficient food for increasing population in Bangladesh requires sustainable growth of agricultural sector. So the key purpose of Bangladeshi agriculture is to provide sufficient food for ever increasing population (Basak, undated). But the soil fertility is declining due to over exploitation of soil resources during cultivation, soil fertility condition of a country influences agricultural productivity and food security and livelihoods 
(Anon, 2002). Therefore, the uses of higher amount of fertilizers have been introduced to attain high yield of various crops for all the growing seasons in Bangladesh.

The use of chemical fertilizers in Bangladesh started increasing after the year of 1975 and significant amount of chemical fertilizer consumption was noted during 1975-76. Afterwards that increasing trends of fertilizers were being observed which reached peak value of 36.50 lakh tons during 2007-08 (Figure 01). For instance, Siddique et al. (2014) reported consequences of conventional agriculture and long term (1991-2002) impacts of chemical fertilizer based farming in Piedmont soil area and concluded that soil fertility characteristics has been decreased such as soil acidity, organic matter content and some plant nutrients have been reached beyond their critical levels. In addition, Micronutrients zinc (64\% decline) and boron ( $82 \%$ decline) has been almost depleted reaching their critical level during the time period 1991 to 2012, and are causing crop productivity and yield decline. However, Basak (undated) reported that along with Urea, TSP and MP, the use of Gypsum, Zinc Sulphate and other micro nutrients were also increased after 1975-76 to supplement plant nutrients requirements.

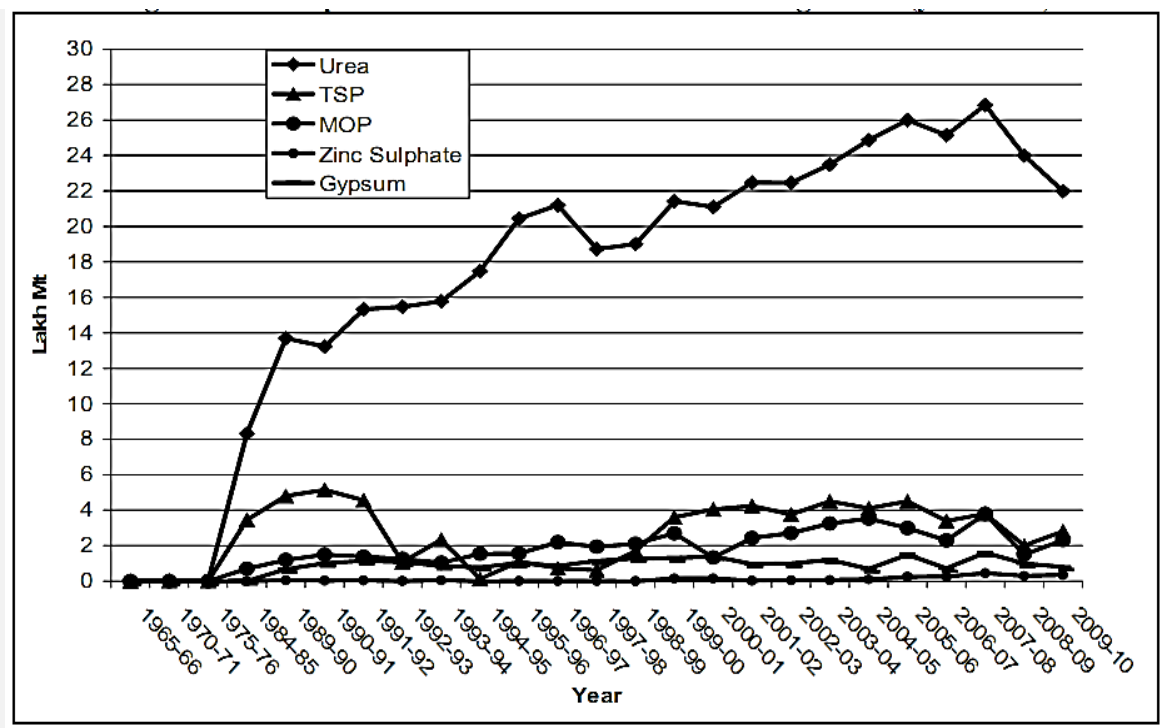

Figure 01. Consumption of different fertilizers in Bangladesh (Basak, undated)

Before the period, 1975-86 maximum farmers cultivated traditional and or local varieties and used organic manures such as cow dung, bone meal etc. After the period of 1975-76, the irrigated area of rice and other crops were increased year after year. In irrigated condition, most of the farmers use HYV rice, which requires high fertilizer dose than local low yielding rice varieties. The HYV acreage and irrigation have a significant positive influence on fertilizer consumption (Basak, undated).

In recent years, several studies have been conducted on fertilizer issues by different organizations in national and international levels in all over Bangladesh. Future impacts scenarios due to excessive use and dependency on chemical fertilizer is also well established for many sectors in different regional scale, but still our farmers are ignorant about it due to lack of knowledge. They only prefer to depend on chemical fertilizers during crop cultivation in their fields; as a result soil is losing its natural productivity and fertility characteristics. Additionally, the integrated environment (soil-air-water continuum) is being imbalanced, polluted and deteriorating rapidly. On the other hand, for higher price of chemical fertilizer the farmers are suffering from financial crisis and return on investment during cultivation of crops. The cost which is required to cultivate the crops is generally higher than the cost which the farmers get from selling the crop in the market. But after facing all these drawbacks, they are yet not willing to use compost fertilizer in their field because they are ignorant about its beneficial impact and as they do not have opportunity and or timely availability of fertilizers from organic sources. However, future fertilizer demand is still increasing day by day due to increasing demand for food, crop diversification and introduction of HYV. Chemical fertilizer processing and production require more manpower, fertilizer industry, gas \& electricity as well as economic resources which is not possible to provide by the government always. In this regard, dependency on organic or compost fertilizer can reduce or compromise chemical fertilizers requirement. Thus, it has become very 
urgent to develop a farmer friendly concept which will help to reduce farmer dependency on chemical fertilizer; and increase the application of organic manures and compost in crop fields so that maintenance of soil fertility would be a reality. The key objectives of the study were to know the local farmers perceptions on organic fertilizer and to reduce their dependency on chemical fertilizer to protect or maintain soil natural fertility. The overall objectives included to know in which crop cultivation compost fertilizer is used and to identify the reasons why farmers are not willing to use compost fertilizer.

\section{Materials and Methods}

Study area: The study area is 'Salua' which is situated in the north-western part of Jessore district and this area is under Phulshara union of Chougachha Upazila. It has land about 2717 ha and population is about 18314. Salua is a populated place and is located in Jessore, Bangladesh. The estimate terrain elevation above sea level is 11 meters. The latitude is about $23^{0} 13^{\prime} 42.92^{\prime \prime}$ and longitude is about $89^{\circ} 6^{\prime} 0.44^{\prime \prime}$. 'Ghior' and 'Ishwardee' soil series dominates in this region and the land type are medium low and medium high land respectively (SLRUG, 2014).

Features of the study area: The total population is about 18314. People of all religion live here. Agriculture and farming is the main occupation here. Besides this, fishing, small business, shop keeping is also practiced here. There are a primary school, a high school, a college, two madrasa, five mosques and 7 other governmental and non-governmental institutions in Salua (Aktar, 2014).

Data collection and analysis: Relevant data were collected from various books, publications, research papers and study reports of the agriculture and fertilizer sector of Bangladesh. Also, field observation and personal interview have been made. Mainly participatory approach was followed for the field research work of the experiment. Field survey was conducted in the selected area. The methods which were applied for primary data collection were questionnaire preparation, survey work, and photograph. The discussion period was not too long and too short but in an appropriate level. In interview period, it was in keen attention in the process of listening, paraphrasing, probing and note taking. Interview was conducted in 50 families. There were also uses of secondary data from books, articles, reports, journals etc. Secondary data has been collected from various sources such as Central library of JUST, Soil Resource Development Institute (SRDI), Ministry of Agriculture (MoA), DAE and Bangladesh Fertilizer Association (BFA) and various internet sources.

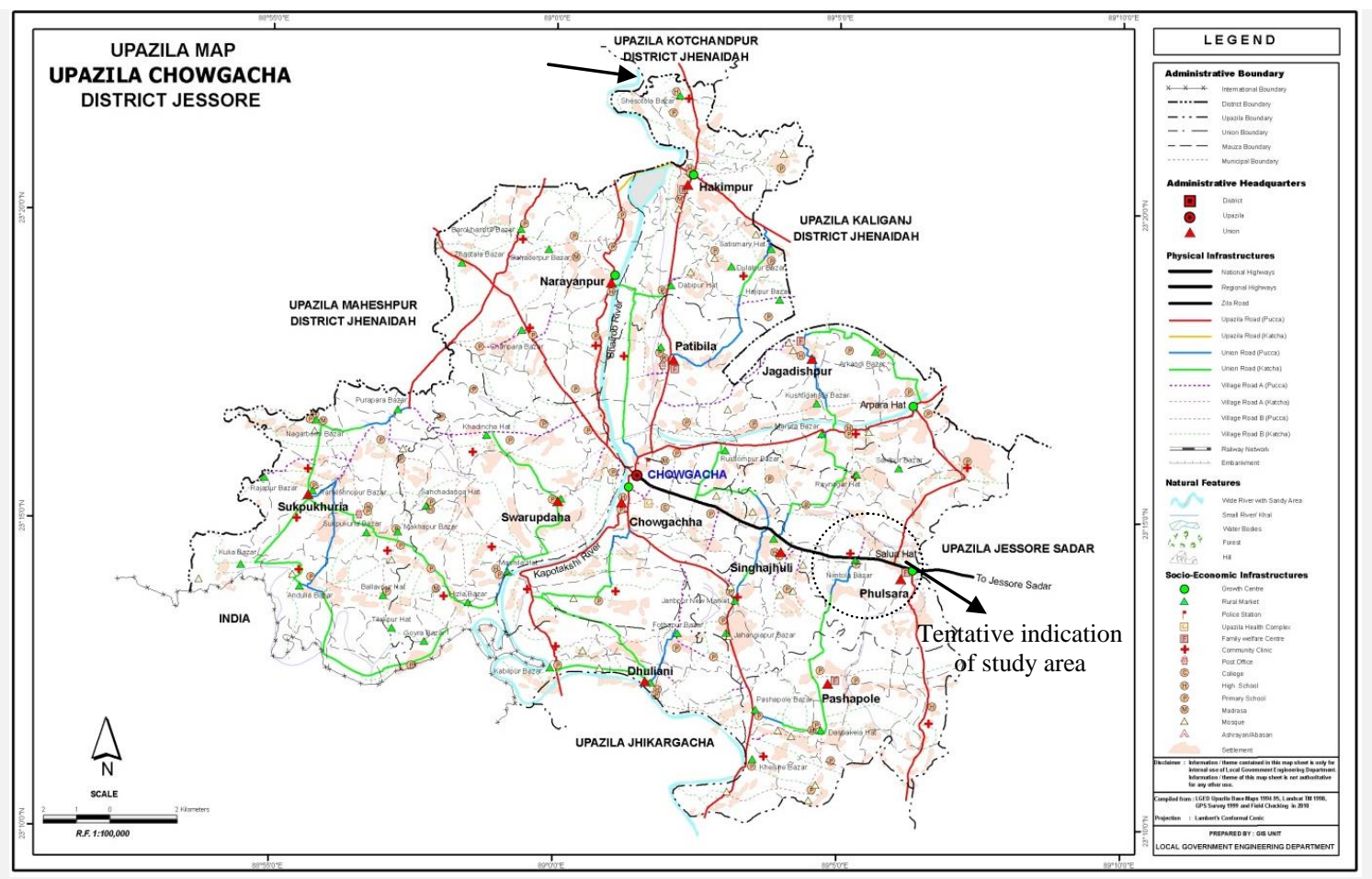

Figure 02. Chougachha Upazila Map of Jessore district (Source: LGED, 2015) 
After data collection and compilation, the next step was to organize and present data in appropriate understanding formats. The findings were presented for the readers in a way so that knowledge could be acquired in a shorter period of time. Most of the data are presented in graphs and pie chart by using Microsoft word and Microsoft power point.

\section{Results and Discussion}

\section{Features of the survey participants or the respondents of study area}

Maximum farmer's age was 21-30, which was about 35\% approximately. Middle aged farmer are also founded in the study area. Figure 03 is showing the age limit of the farmers.

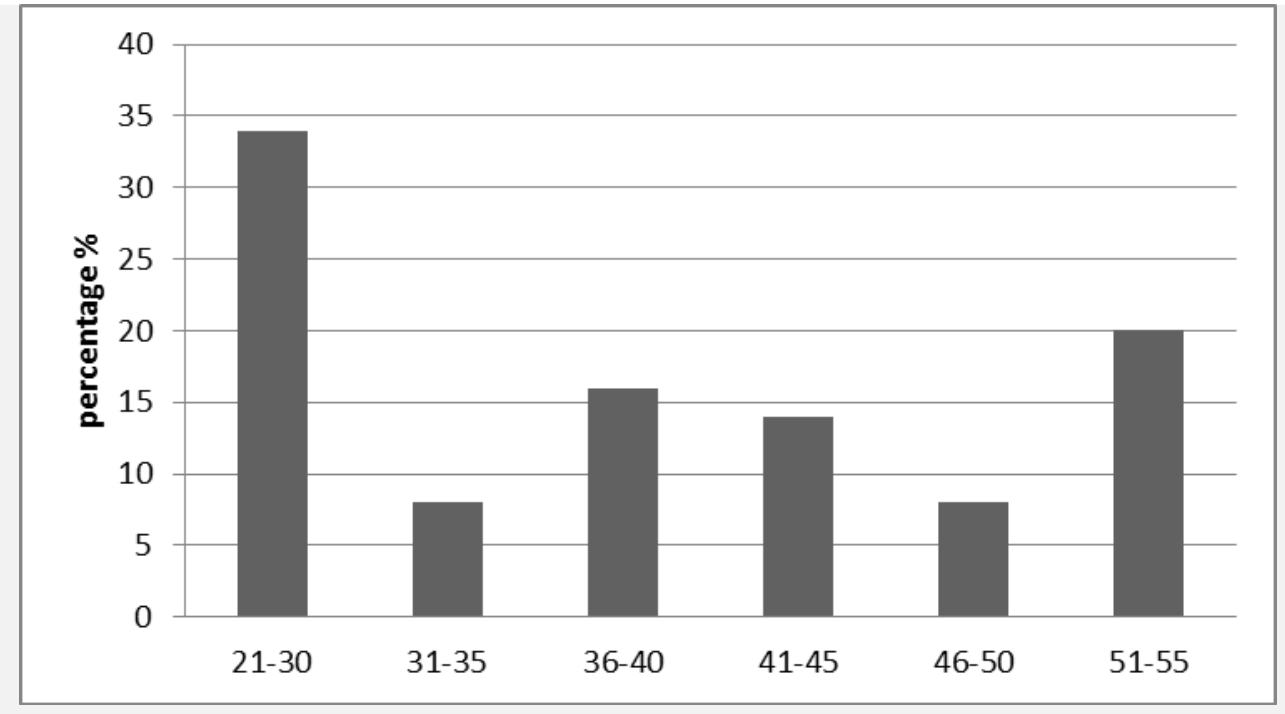

Figure 03. Age range of the participants in Salua Area of Chougachha upazila, Jessore

\section{Educational level}

From the field survey, it was found that the educational level of the participant farmers was disappointing (i.e., illiterate or less educated or primary education only) which may be the main cause of their existing traditional farming behavior. About 34\% farmers in Salua area were still uneducated and $36 \%$ has completed their primary education. H.S.C and higher level educated farmer was not almost absent. The concern and consequences about fertilizer uses and its long term impacts in the environment and future crop production capability was found very insignificant. The residents of the study area were only acknowledged that compost fertilizer is able to remove pests-diseases and capable of increasing soil fertility.

\section{Level of income of the farmers}

Most of the farmers were poor and their monthly income is about less than 5 thousand which was case of above $45 \%$ respondents. Although they are living in such poor standard, still they use expensive chemical fertilizer to attain higher yield which is a burden to them. Thus, balanced fertilizer management and reduction of dependency on chemical fertilizer can be a good solution against the existing conventional farming of the studied area.

\section{Farm size of respondents in the study area}

Most of the farmers don't have enough land; they mostly were marginal farmers, some were small scale farmers and few were medium scale farmers. The crop yield and return they get from their land is not sufficient to run their livelihood; and most of the time they rely on buying foods from the markets. This quantity of little land can be an important reason why they depend highly on chemical 
fertilizer, more precisely most the respondents remain unable to become independent farmer with own various resources. They thought that as their land area is scare or some in quantity, so become motivate to grow more chemical fertilizer based crops and it seems the only way out for them considering circumstances. Some farmer practices combined use of compost (such as cowdung, house hold residues etc.) and chemical fertilizers but number of these types of farmers were found in a lower quantity.

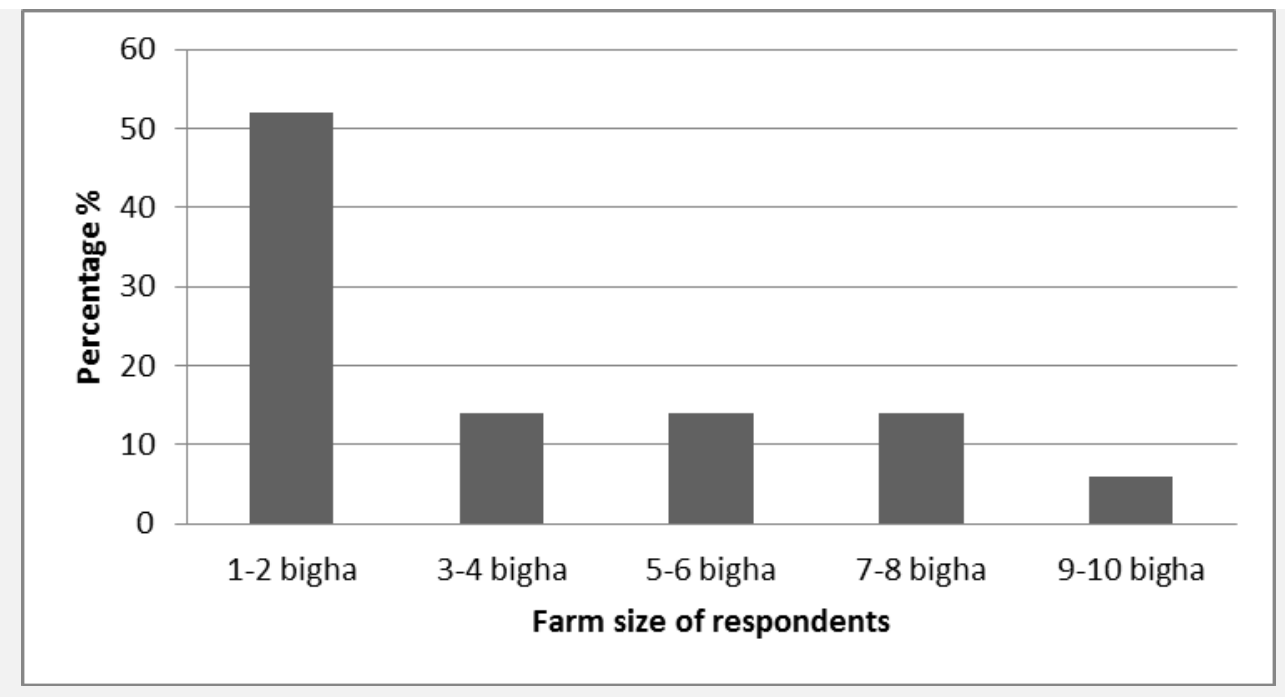

Figure 04. Farm size of respondents where 1 'Bigha' is usually considered as equivalent of 33 decimal of land area in Bangladesh

\section{Pattern of fertilizer usage}

Farmers of the study area practices usual conventional farming, and highly depend on chemical fertilizer for higher crop yield. Data shows that fertilizer usage pattern of the farmers as about $44 \%$ compost fertilizer and the usage of chemical fertilizer is about $56 \%$.

\section{Cropping pattern in Salua area of Chougachha upazila of Jessore district}

In the study area, diversified crop cultivation practices have been identified e.g. cereals (i.e. paddy, and wheat) pulses, potato, vegetables and even economic crops like jute and maize. Most of the farmers cultivate paddy. Aus (Pre-monsoon rice), Aman (Wet season rice) and Boro (Dry season irrigated rice) rice are the main types of rice based cropping pattern but they also cultivate some hybrid rice varieties. Almost all the farmers cultivate rice on their fields; besides rice they cultivate some vegetable, potato, pulse and jute. Farmer's worse farm size is higher cultivating all types of crop shown in Figure 05.

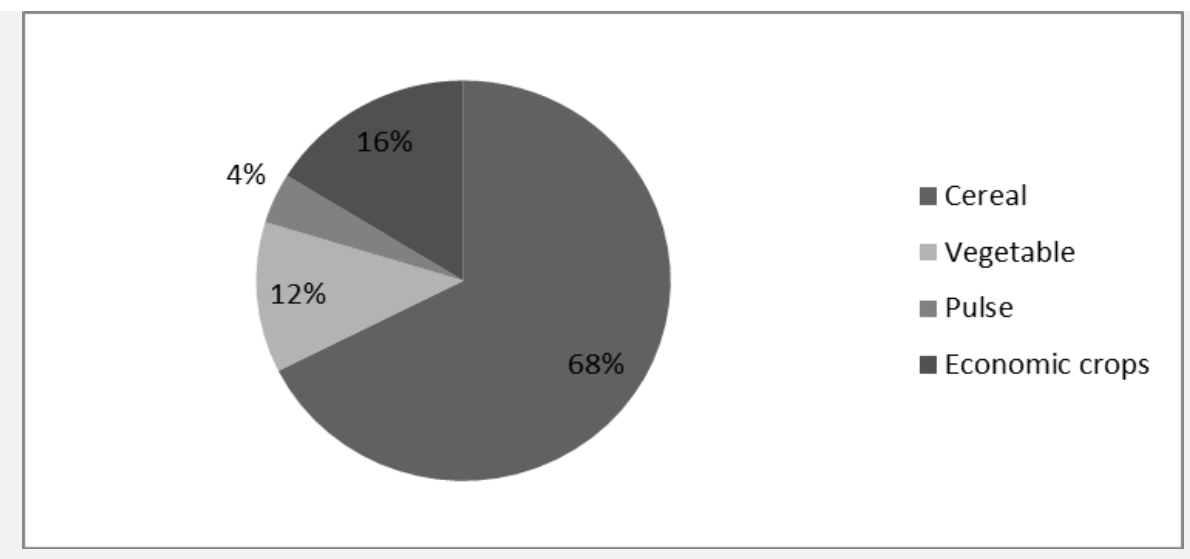

Figure 05. Cropping pattern of the study area 


\section{Reasons of using chemical fertilizer by farmers}

According to the study, it is shown that almost 56\% people in Salua area are using chemical fertilizer for their cultivation practices. There are several socio-economic reasons for chemical fertilizer based farming; firstly, farmers believed that when chemical fertilizer used in the field, their field crops might be highly productive, as responded about $84 \%$ of farmers. Secondly, the economic conditions do demand the uses of compost fertilizers in their crops as most of the farmers are living below the poverty line and they have a little amount of land or contracting land from others for season based cropping. It is not possible to get their desired crop yield only by applying compost fertilizer in their field. Thirdly, the lacking of harassment in getting chemical fertilizer than compost fertilizer as they have no sources of compost fertilizers, i.e., organic fertilizer is not available sufficiently in the area during growing seasons (Figure 06). Fourthly, there were no governmental or non-governmental agencies to supply compost fertilizer to that local farmer of Salua area.

From the field survey, there were some other reasons identified for usage of chemical fertilizers by farmers. The respondents consider that chemical fertilizer is helpful in growing high yield varieties which is not possible by compost fertilizers, and they do not want to take risk by using only compost fertilizer and nutrients of chemical fertilizer have direct effect on plant growth and subsequent yields. Chemical fertilizers are usually quite high in respective plant nutrient and only relatively small amounts are required for crop growth and developments.

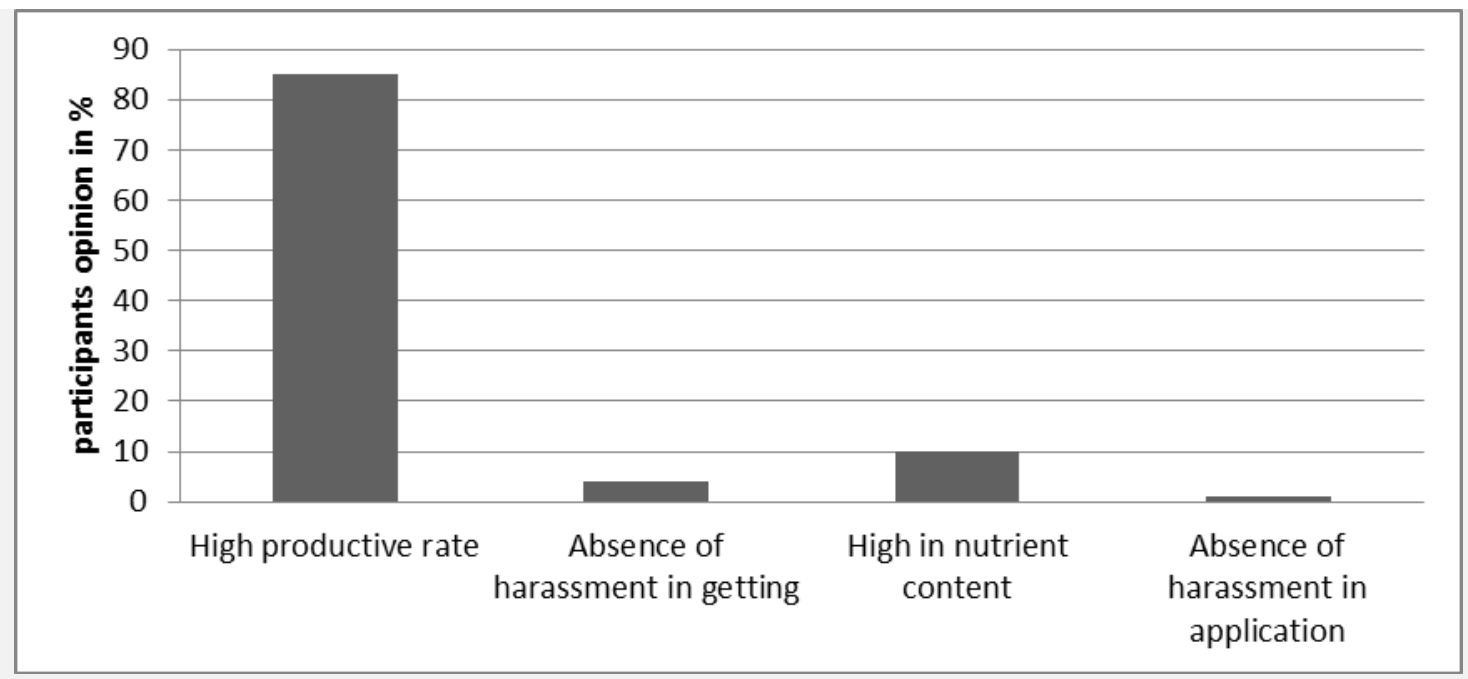

Figure 06. Participant's opinion about reasons of using chemical fertilizer

\section{Reasons of using compost fertilizer by farmers}

In Salua area, $46 \%$ of the farmers are using compost fertilizer in their farmland. All these farmers are combined user that is they use compost and chemical fertilizer in combination. They use it for its disease removing capability that is it is able to protect the plant from various diseases and insects. From their point of view, it reduces the application of pesticides, at the cost of decreased yield. This was stated by almost $95 \%$ of compost fertilizer users (Figure 07 ).

The farmers who have cows of their own it is easy to get compost fertilizer to them. They find organic fertilizer of low cost or no cost. Farmers believe application of organic manures result good to the soil, so they use compost fertilizer in their soil during cultivation. From the farmer's point of view of Salua area, application of compost fertilizer requires a lower amount of chemical fertilizers application which saves cost, so they are willing to use compost fertilizer in their farmland. 


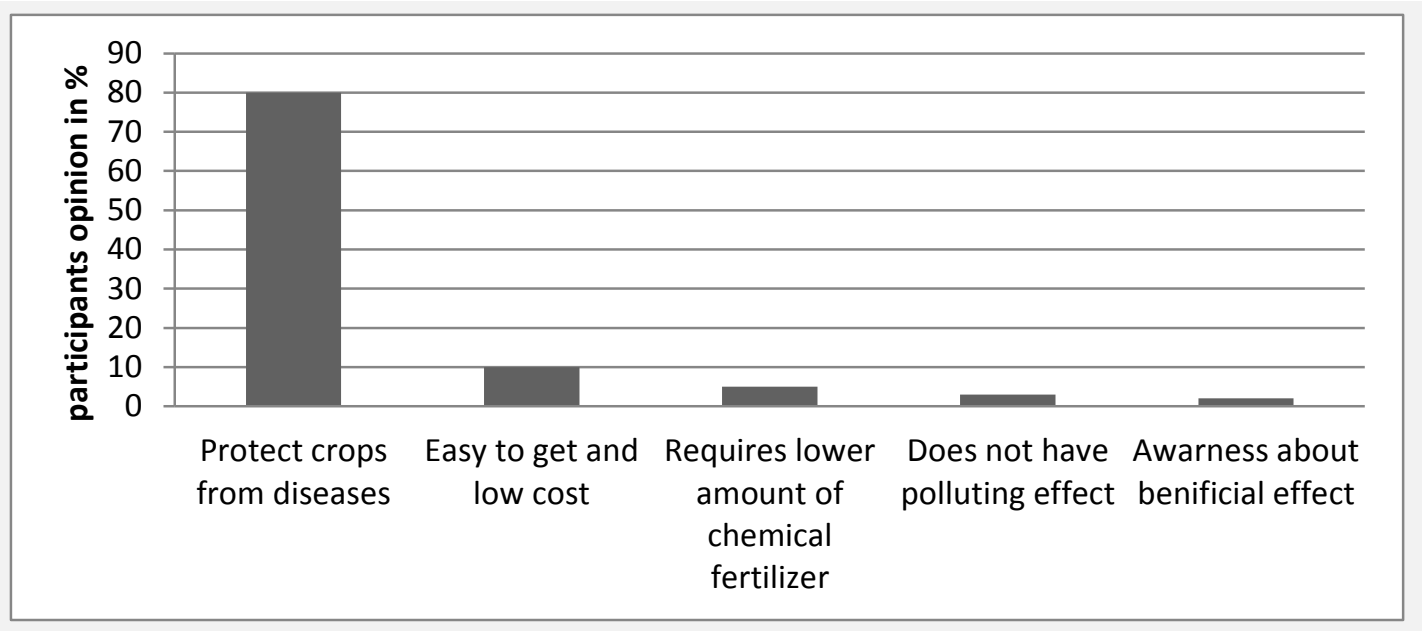

Figure 07. Participant's opinion about reasons of using compost fertilizer

Compost fertilizer improves long term productivity of soil; it acts like soil conditioner that makes the soil softer which is required for optimum crop cultivation. It adds nutrient to the soil as well. In many part of Bangladesh, compost fertilizer is mainly used in vegetable cultivation because compost fertilizer contributes to the residual pool of organic N and P in soil. Some farmers also mentioned that compost fertilizer is good as it does not pollute water, soil and it is not poisonous as the chemical fertilizer so they are willing to use compost fertilizer in their field if the responsible sector takes some steps to improve nutrient concentration in compost fertilizer. Sometimes, the fuel price and the imported fertilizer price become so high that force the farmer to use compost fertilizer in their field. Beside, these some farmers which are educated are aware of the beneficial effect of compost fertilizer in their field as discussed before.

\section{Reasons behind not to use (or prefer) only compost fertilizer}

In the study area, the main reason of not using compost fertilizer instead of chemical fertilizer is the traditional fertilization practice. Not only in Salua area but in every place of Bangladesh, most of the farmer depends on chemical fertilizer for their cultivation. It is a traditional practice to use chemical fertilizer in cultivation though it requires high price but farmers believed that only chemical fertilizer can give them desired yield of their high yield varieties crop and they need more yield to live happily. Thus, they prefer to depend much on chemical fertilizer instead of compost/organic fertilizer. They do not know or aware of the good or bad side effects of chemical fertilizer, because they use it as it is traditional fertilization pattern from last few decades.

The compost fertilizer which is produce in Salua area requires a simple process that is the farmer keeps their cow dung for a long time (1.5-2 month) in a hole and then apply it in the field. The compost fertilizer which is made in this process contains very lower amount of nutrient which is not enough for all kind of crop cultivation. This compost may be good for the cultivation of some vegetable like eggplant, tomato, papaya, pumpkin, various types of bean etc. but its application for the cultivation of rice, jute, wheat and other crops not such fruitful, as the farmers view. In case of this, compost fertilizer is preferably applied for removing diseases and pests. So it becomes risky to depend on this lower nutrient contained compost fertilizer instead of chemical fertilizer as application of chemical fertilizer in these crops is useful.

\section{Conclusion \& Recommendations}

Bangladesh is a densely populated country and the amount of its cultivable land is shrinking in proportion of its population and most of the rural people are living below the poverty line. On the other hand, food demand is increasing day by day with increasing population so cultivation of HYV crops has become a common practice. In most of the family of the study area, agriculture is the main source of income but often the farmer do not get sufficient amount of money on crop yield return 
because of high cultivation and inputs cost. High price of chemical fertilizer and acute dependency on chemical fertilizer is prime reason of it.

Effort should be made to ensure sufficient supply of compost fertilizer during growing seasons. Government and private sector NGO's should come forward. Proper knowledge about the beneficial impact of compost fertilizer should be given to the local farmers. Various TV programs like 'Hridoy e Mati o Manush', 'Krishi Dibanishi' should be held which will make the farmer aware and make them willing to use more and more compost fertilizer in their cultivation practices.

Combined support is needed through efficient intervention and appropriate policies, organizations and research and extension activities. At present, the extent of compost availability is limited by few authorized commercial producers in the market like Annapurna Agro Service, Waste Concern, Grameen Shakti and Rural Development Academy (RDA). However, development facilitators such as Katalyst, Innovision Consulting Pvt. Ltd., donor agencies etc. and enterprises like Rash Agro Enterprise, Achme Laboratories, etc. should come forward to work for the promotion and availability of compost and organic manures in Bangladesh. The research and extension institutions should bridge the farmers' access to the most appropriate and cost effective composting technologies.

\section{References}

[1]. Aktar, M. A. (2014). Information about Salua area of Chougachha upazila, Jessore, Bangladesh (Conversation) [Personal communication, dated 06/05/2014].

[2]. Anon (2002). Soil fertility and Nutrient Management, DFID and the Netherlands Ministry of Foreign Affairs. Available at http://www.odi.org.uk/keysheets.

[3]. GoB, (2009). Bangladesh Economics Review, 2009, Ministry of Finance, Dhaka, Bangladesh.

[4]. Basak (undated). Future Fertilizer Demand in Bangladesh, Unnayan Onneshon, Dhaka, Bangladesh.

[5]. LGED, (2015). Local Government Engineering Department (LGED) Maps. Retrieved 22 March from http://www.lged.gov.bd/ViewMap.aspx

[6]. Siddique, M. N. A., Halim, M. A., Kamaruzzaman, M., Karim, D. \& Sultana, J. (2014). Comparative Insights for Investigation of Soil Fertility Degradation in a Piedmont Area which Cover the Anjamkhor Union of Baliadangi Upazila, Thakurgoan, Bangladesh. Journal of Environmental Science, Toxicology and Food Technology, 8(4):82-87.

[7]. SLRUG, (2014). Soil and Land Resource Utilization Guide/Chougachha 'Upazila Nirdashika', Jessore, Published by Soil Resource Development Institute (SRDI), Ministry of Agriculture, Dhaka. 